\title{
Research on the Factors Influencing the Employment of Graduates of Tongren Preschool Normal College
}

\author{
XU ZONGMIN ${ }^{1,}$, , SHANG HONGYAN ${ }^{2, b}$
}

${ }^{1}$ Panyapiwat institute of management, Bangkok, Thailand

${ }^{2}$ Panyapiwat institute of management, Bangkok, Thailand

Key words: normal school; College; Graduates; employment

\begin{abstract}
The major of normal education has always been highly concerned by the government and society. Because students shoulder the important task of teaching and educating people after employment, our country has invested a lot of manpower, material and financial resources in the cultivation of normal education specialty. With the continuous reform of China undefined social and economic system, the employment situation in China is quite serious. Under the environment of great employment pressure, the employment situation of teachers majoring students graduated from many higher professional schools has been paid more and more attention by all walks of life. The employment situation of normal college students is not only related to their personal development, but also has an important impact on the development of society.

According to the references, the factors of employment influence and the factors of employment influence are analyzed in the aspects of labor supply, demand, supply demand and so on, and the result analysis is carried out in the following logic order. Further, the article carries on the theoretical analysis and demonstration, and uses a variety of empirical analysis methods of the SPSS software to verify the influence factors of the employment of the college graduates. Finally, the relevant conclusions of the theoretical analysis and the empirical analysis are combined.
\end{abstract}

\section{铜仁幼儿师范高等专科学校毕业生就业影响因素研究 \\ 徐宗敏 ${ }^{1, a}$, 尚鸿雁 ${ }^{2, b}$ \\ 1 泰国正大管理学院, 曼谷, 泰国 \\ 2 泰国正大管理学院, 曼谷, 泰国 \\ 2420757855@qq.com}

关键词：师范学校；高等专科学校；毕业生；就业

中文摘要.师范教育专业始终受到政府和社会的高度关注, 因其就业后肩负着教书育人的重要 使命，在培养师范教育专业方面倾注了许多的人力、物力、财力。随着我国社会经济体制不 断变革, 我国的就业形势相当严峻, 巨大的就业压力环境下, 许多高等专业学校毕业的师范 专业学生就业情况持续受到社会各界的关注, 师范专业学生的就业情况不仅关乎其个人的发 展，对社会的发展也有重要的影响作用。

本文对文献进行了梳理, 并对铜仁幼儿师范高等专科学校毕业生就业影响因素, 通过劳 动力供给、需求、供给需求等方面进行分析就业影响因素, 跟随逻辑顺序进行了调查结果分 析, 并进一步进行理论分析论证, 运用 SPSS 软件的多种实证分析方法对高校毕业生就业影 响因素作验证; 最后结合理论分析和实证分析的相关结论。 


\section{1.引言}

\section{1 研究背景}

随着我国经济发展形式的不断改革, 高等专科教育逐渐开始普及化, 更多的人有了进入 高等专科学校深造的机会, 通过接受高等教育为日后的发展储备力量, 同时为日后开展相关 工作奠定良好基础。然而随着高等专科学校招生规模不断扩大, 市场经济体制的不断变革, 农村地区人口不断向城市转移, 以及 $985 、 211$ 等院校毕业的大学生、研究生逐年增加, 专科 学校大学生的就业空间受到一定程度的挤压, 就业压力不断地增大。国家领导高度重视大学 生这一群体的就业问题, 并始终坚持探索如何提升高等专科学校大学生的就业率。本文基于 前述背景, 对铜仁幼儿师范高等专科学校毕业生就业影响因素进行了系统的分析。

\section{2 研究意义}

高等专科学校毕业生是我国市场劳动力的主要来源之一, 若人才不能得到很好地利用, 进行科学的资源配置, 将会在一定程度上对人才造成浪费, 增加我国市场劳动力运转成本, 同时也是党和国家的负担。因此, 在经济不断转型的时期, 应及时探索和掌握高度专科学校 毕业生就业难的根本原因。

\section{2. 文献综述}

新疆师范高等专科学校招生就业处丛新婷与马桂萍教师，在《专科毕业生就业中存在的 问题及对策分析一以新疆师范高等专科学校为例》中提出, 少数民族地区有自己独特的现 状,多民族聚居、文化多元、语言多元, 城乡之间、城市与城市之间经济发展不平衡。因此, 在 语言文化多元的人文环境及城乡之间、城市之间经济发展不平衡的社会环境背景下, 容易产 生对幼师毕业生就业质量的直接或间接影响。

\section{3. 研究目的}

\section{1 研究内容}

本论文题目来源于导师提供的课题, 实证调查数据是通过调查和实证, 并参照 2018 年毕 业生就业情况数据获得。本文主要内容基于就业经典理论基础上, 进而从劳动力供给、需求、 供给需求等方面进行分析就业影响因素。进而将铜仁幼儿师范高等专科学校毕业生抽样调查 做进一步验证, 最后通过理论与实证分析相结合的方法, 系统分析毕业生就业影响因素, 并 提出相关建议。

\section{2 研究思路}

基于当前高校毕业生就业问题面临的现实情况，进而得到了问题的研究探索方向。本文 最终确定研究目标为探索铜仁幼儿师范高等专科学校毕业生就业影响因素, 依据经典理论的 引导, 通过对铜仁幼儿师范高等专科学校毕业生就业的总体状况分析获取现实因素, 进而为 接下来的理论与实证分析奠定良好基础。通过理论与实证分析得到铜仁幼儿师范高等专科学 校毕业生就业影响因素，完成论文研究的目标，最后将影响因素进行整理和分析。

\section{4. 研究方法}

\section{1 理论分析法}

本文通过经济学角度出发, 立足于相关理论, 针对铜仁幼儿师范高等专科学校毕业生就 业问题进行分析, 并总结当今时代毕业生就业问题的总体情况, 继而通过供给、需求、供给 需求等反面进行相关理论论证, 进而分析铜仁幼儿师范高等专科学校毕业生就业影响因素。 


\section{2 实证分析法}

本文通过铜仁幼儿师范高等专科学校毕业生就业抽样调查结果作为分析依据, 运用因子 分析、交叉表分析等方法对理论分析结果进行进一步论证, 并总结铜仁幼儿师范高等专科学 校毕业生就业影响因素。

4.2.1 铜仁幼儿师范高等专科学校毕业生就业影响因素理论分析

（1）劳动力供给的影响因素

铜仁幼儿师范高等专科学校同样是市场劳动力重要的供给群体之一，承担着重要的使命 和责任, 当今严峻的就业形势导致许多毕业生无法找到合适的工作, 相对而言, 严峻的形势 既是压力也是动力, 毕业生在就业过程中受到多种因素影响, 其中保留工资、社会资本、人 力资本、择业要求、就业偏好等方面都是较为主要的影响因素。

(2) 劳动力需求的影响因素

劳动力需求指的是劳动力在一段时期内的需求量, 企业获取的劳动力数量。社会需求量 大, 毕业生在就业时便会有更多的选择机会, 更容易促进就业, 反之则会对毕业生的就业率 产生很大程度上的影响, 毕业生的选择范围被缩小, 导致许多幼儿教师在毕业后无法从事本 职工作, 社会的运行成本也因此受到影响。因此, 社会需求因素是毕业生就业影响的主导因 素。

(3) 劳动力供需混合影响因素

在经济学角度进行分析过程中，因素不仅仅是供给因素以及需求因素，同时还包含着货 币政策、财政政策以及就业信息等, 因此, 我们在分析过程中, 将劳动力供需混合因素这一 概念融入其中, 使探讨更加准确和便捷。针对铜仁幼儿师范高等专科学校毕业生就业影响因 素理论分析中最重要的就业信息传递进行分析。

4.2.2 铜仁幼儿师范高等专科学校毕业生就业影响因素研究实证分析

(1) 数据来源及说明

全国高校毕业生就业信息管理与监测系统、贵州省大中专毕业生就业信息平台; 数据统 计截止日期为 2018 年 12 月 21 日; 使用数据主要涉及毕业生的规模和结构、就业率、毕 业去向、就业流向等方面。通过对铜仁幼儿师范高等专科学校进行网络问卷调查以及实地调 查得到的数据资料。

\section{3 问卷分析方法}

通过对铜仁幼儿师范高等专科学校毕业生就业进行调查, 计算高校毕业生就业率公式为: 毕业生就业率 $=$ （已毕业人数/毕业生总人数）*100\%

\section{5. 研究结果}

\section{1 毕业生总体毕业率}

截止 2018 年 12 月 21 日, 铜仁幼儿师范高等专科学校毕业生达到 2937 人, 总体就业率 为 $92.94 \%$ 。 


\section{2 各学院及专业毕业生就业率}

表 1: 各学院及专业毕业生就业率

\begin{tabular}{|c|c|c|c|c|}
\hline 学院 & 专业 & 总人数 & 已就业人数 & 就业率（\%) \\
\hline \multirow{3}{*}{ 学前教育学院 } & 学前教育 & 1739 & 1615 & 92.87 \\
\hline & 特殊教育 & 46 & 44 & 95.65 \\
\hline & 小计 & 1785 & 1659 & 92.94 \\
\hline 初等教育学院 & 小学教育 & 993 & 917 & 92.35 \\
\hline \multirow{5}{*}{$\begin{array}{c}\text { 艺术与体育 } \\
\text { 教育学院 }\end{array}$} & 音乐教育 & 89 & 86 & 96.63 \\
\hline & 体育教育 & 164 & 152 & 92.68 \\
\hline & 美术教育 & 91 & 85 & 93.41 \\
\hline & 舞蹈教育 & 38 & 38 & 100 \\
\hline & 小计 & 382 & 361 & 94.50 \\
\hline 总计 & & 3160 & 2937 & 92.94 \\
\hline
\end{tabular}

\section{8届毕业生各专业就业情况}

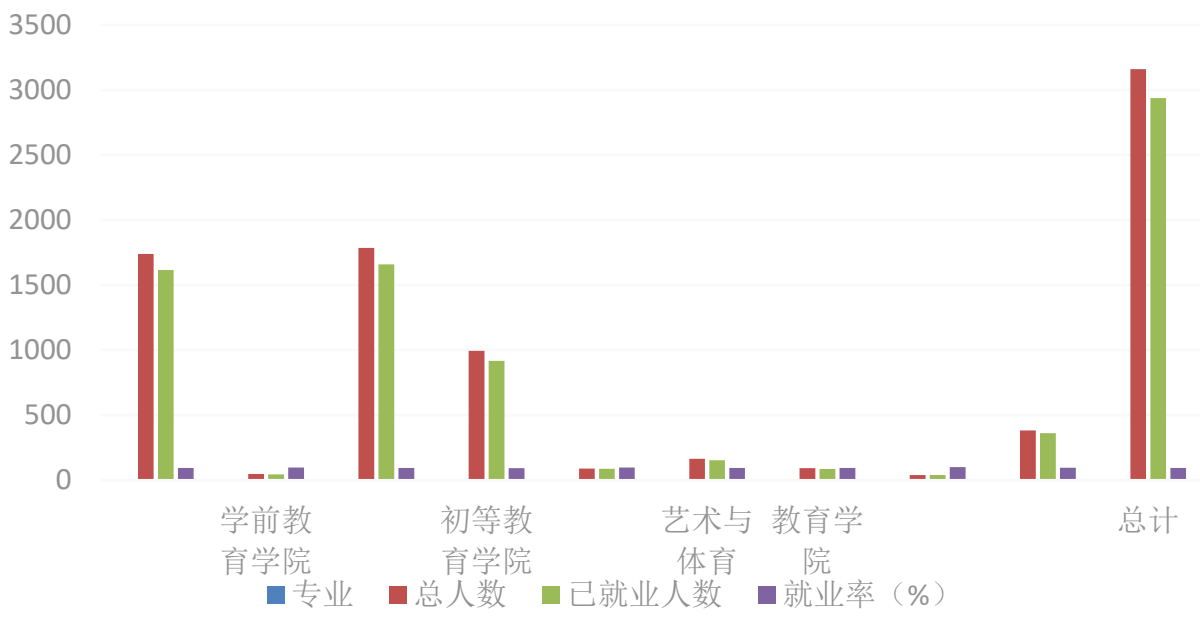

图 12018 届毕业生各专业就业情况

\section{6.总结与讨论}

\section{1 总结}

通过对铜仁幼儿师范高等专科学校毕业生就业影响因素理论分析，总结出主要受到劳动 力供给的影响、劳动力需求的影响、劳动力供需混合影响。

通过铜仁幼儿师范高等专科学校毕业生就业影响因素研究实证分析, 铜仁幼儿师范高等 专科学校进行网络问卷调查以及实地调查得到的数据资料。毕业生总体毕业率截止 2018 年 12 月 21 日, 铜仁幼儿师范高等专科学校毕业生达到 2937 人，总体就业率为 $92.94 \%$ 。

\section{2 讨论关于促进就业的建议}

(1) 加强积累社会经验

毕业生在毕业后参与应聘过程中，通常会在招聘时说明，有相关经验者优先录用。因此， 高校毕业生的社会经验在进行应聘过程中有着重要影响作用, 应在高校学习和生活中不断积 累自身社会经验, 可以在不影响专业课学习的情况下, 寻找相关社会实践工作, 进而能够丰 富自己的社会经历, 帮助自己未来踏入职场提供良好的经验基础。参与社会实践的方式较多, 无论是高校组织还是自己寻找机会, 都应在工作中努力进取, 认真对待自己的实习机会。大 
学时光实则非常短暂, 能够利用有限的实践获取更多的经验对大学生成长具有积极地作用。 可以将寒暑假都合理规划利用, 这些实践能够有效帮助学生积累社会经验, 进而在参与工作 时更具核心竞争力。

(2) 树立正确择业观念

高校应帮助毕业生树立正确的择业观念，在遇到困难时沉着冷静，不放弃，客观理性的 分析理想与现实, 真正清晰自己的实际情况, 了解自己适合干什么能够干什么是最重要的。 对自己有清晰准确的定位能够帮助自己在应聘过程中，保持冷静和积极地心态，始终秉持着 自己的初心, 遇到问题不气馁才能顺利就业。为此, 思政教育是帮助学生树立正确思想观念 的有效路径, 高校应加强思政教育, 指导学生对自己进行定位, 在就业过程中应从长远角度 来看, 不能只关注薪资待遇, 同时需要重视社会发展需要。高校可开设专门的就业指导部门, 帮助学生正确树立就业观念, 培养大学生的社会责任感, 以及实事求是的工作品质。

(3) 加强学生心理辅导

即将步入社会的大学生, 正处于从学习生活走向工作生活的重要转折阶段, 基于父母对 自己的期望以及自身对工作的期许, 面对激烈的劳动力市场竞争, 许多大学生均会感到迷茫 和无所适从，甚至心理上会受到一定程度上的冲击，容易出现心理问题。为此，高校开展就 业指导工作时应注重对大学生的心理疏导工作，使大学生积极地面对工作生活。高校可以通 过引导, 使学生充分了解现阶段的社会形式, 转变大学生的思想观念, 不是只有到国企或事 业单位才能实现自己的理想, 现在许多新型岗位更适合高校毕业生的发展, 在不同岗位上只 要努力都能实现自我价值, 为社会做出贡献。

(4) 开展校企合作模式

企业作为人才的需求方, 高校作为人才的供给方, 加强高校与企业合作能够帮助学生更 好的就业。高校与企业可共同建立人才培养机制, 并为高校学生提供适合的实习岗位, 使学 生在学校接受一定的理论知识学习后，便可到企业进行工作实习，为学生将来就业奠定良好 的经验基础。高校在教学过程中, 也可邀请企业具有丰富经验的员工, 为高校学生进行实习 指导, 使学生能够深入理解企业工作岗位的基本流程, 也有利于学生清晰自己的未来工作规 划, 在企业进行跟岗学习、顶岗实习等, 能够使高校毕业生更加适应工作环境, 为将来的工 作做过渡，通过校企合作的模式有利于促进双方利益最大化。

\section{References}

[1] Wang Ziheng, $\mathrm{Pu}$ Zhilin, Zhang Yuhan. Investigation Report on the Willingness of Undergraduate Non-free Normal Students to Teach at the Grass-roots Level - Taking Beijing Normal University as a Sample. J. Human Resources Social Security of China, vol.1, pp: 37-38.2018

[2] Shang Yingmei. Follow-up study on the 10th anniversary of the implementation of free normal students' employment policy --- Take five free normal students of Northeast Normal University as an example. Education Research, vol.12, pp: 141-146.2017

[3] Liu Yarong. Teaching Quality Analysis and Teaching Mode Exploration of Employment Guidance Course in Colleges and Universities - Taking Normal Graduates as an Example. J. Journal of Mudanjiang Institute of Education, vol.6, pp: 60-62. 2018

[4] Shang Yingmei, Yu Shuang. Follow-up Study on the Implementation of Free Normal Students' Employment Policy: Current Situation, Effectiveness and Measures: Taking the Five Free Normal Graduates of Northeast Normal University as an. J. Journal of Northeast Normal University (Philosophy and Social Sciences Edition), vol.5, pp: 195-199.2018

[5] Wang Z.H, Pu Z.L, Zhang Y.H. Survey report on grassroots teaching willingness of underg Raduate non-free normal university students -taking Beijing normal university as a sample. 
China human resources social security, vol.1, pp: 37-38.2018

[6] Shang Y.M. Tracking research on the $10^{\text {th }}$ anniversary of the implementation of the Employ ents in northeast normal university. Education research, vol.12, pp:141-146.2017

[7] Liu Y.R. Teaching quality analysis and teaching mode exploration of college employment guidance courses - a case study of normal college graduates. Journal of Mudanjiang college of education, vol.6, pp: 60-62.2018 